\begin{tabular}{|l|l|l|}
\hline \multicolumn{2}{|c|}{ PublisherInfo } \\
\hline \hline PublisherName & $:$ & BioMed Central \\
\hline \hline PublisherLocation & $:$ & London \\
\hline \hline PublisherImprintName & $:$ & BioMed Central \\
\hline \hline
\end{tabular}

\title{
Organogenic role of B lymphocytes in mucosal immunity
}

\begin{tabular}{|l|l|l||}
\hline \multicolumn{2}{|c|}{ ArticleInfo } \\
\hline \hline ArticleID & $:$ & 217 \\
\hline \hline ArticleDOI & $:$ & $10.1186 /$ ar-2000-66768 \\
\hline \hline ArticleCitationID & $:$ & 66768 \\
\hline \hline ArticleSequenceNumber & $:$ & 174 \\
\hline \hline ArticleCategory & $:$ & Paper Report \\
\hline \hline ArticleFirstPage & $:$ & 1 \\
\hline \hline ArticleLastPage & $:$ & 4 \\
\hline \hline & & RegistrationDate : 2000-1-5 \\
ArticleHistory & $:$ & OnlineDate \\
\hline \hline ArticleCopyright & $:$ & Current Science Ltd2000-1-5 \\
\hline \hline ArticleGrants & $:$ & \\
\hline \hline ArticleContext & $:$ & 130753311 \\
\hline \hline
\end{tabular}


Thomas Dorner, ${ }^{\text {Aff1 }}$

Affl Charite University Hospital, Berlin, Germany

\section{Keywords}

B cells, lymphocytes, mucosa, organogenesis, Peyer's patches

\section{Context}

Gut-associated lymphoid tissue (GALT) consists of highly organized Peyer's patches (PPs) in the small intestine and intra-epithelial lymphocytes. The intestinal surface of PPs is characterized by the presence of follicle-associated epithelium (FAE)-covering "domes", regions lacking intestinal villi. M cells are found in these domes lacking microvilli on their apical surface. Therefore, the term M denotes microfold or membranous cells that are able to tunnel pathogens through the cytoplasm to the basal surface, allowing close contact with lymphocytes and macrophages. It has been shown that M cells of the respiratory epithelium can serve as the entrance gates for pathogens, such as mycobacteria (Teitelbaum et al, Immunity 1999, 10:641-50 [Abstract]). Previous in vitro studies showed that a B-cell lymphoma could effectively convert epithelial cells into M cells. This study analyzed whether B cells are responsible for the generation of $\mathrm{FAE}$ and $\mathrm{M}$ cells in vivoand whether B cell deficiency could affect transepithelial transport of an enterally-transmitted retrovirus.

\section{Significant findings}

Lack of B cells, due to knockout of either the ? membrane segment (Igh-6) or JH segments of Ig genes (JHD), caused a diminution of detectable PPs, whereas TCR-deficient mice, independently of the TCR subtype, had normal numbers of PPs. The strongest PP deficiency was observed in mice lacking both B and T cells (RAG1 KO mice). In B-cell-negative mice, the size of PPs was much smaller and FAE was abnormal. Transgenic expression of a membrane-bound IgM (mIgM) on the JHD background, allowing generation of B cells with surface but not secreted $\operatorname{IgM}$, could be shown to completely restore the development of PPs and FAE.

Whereas $\mathrm{M}$ cells could be found in abundance in the large domes in the PPs of normal mice, only a few cells with a characteristic microfold surface could be detected in the smaller domes of B-celldeficient animals. In addition, cells with an unusual brush border, most likely $\mathrm{M}$ cell maturation intermediates, were identified in mice without B cells. Reconstitution of B cells by mIgM transgene expression resulted in the complete development of both FAE and M cells. Absence of sufficient T cells 
did not have any significant influence on FAE and M cell development. Finally, RAG1 KO mice did not develop proper domes and lacked M cells.

Elimination of either T cells, with appropriate V chains, or B cells abrogated MMTV infection. Thus, $B$ cells may be needed both for T cell activation and for M-cell-dependent translocation of MMTV. Chimeras with a reconstituted immune system but with underdeveloped FAE were shown to be significantly resistant to MMTV infection. In all TCR KO (having intact B and M cells) recipients of B6 bone marrow, MMTV infection was readily detectable.

\section{Comments}

Although this study does not address any direct aspect of autoimmunity, it provides conclusive evidence for a further regulatory role of B cells; despite their implications as precursors of antibodyproducing cells and antigen-presenting cells this might become of importance for autoimmune diseases. In this context, environmental factors are candidates to be involved in the etiopathogenesis of several autoimmune entities. Whereas this particular study demonstrated the impact of B cells deficient in their antigen receptor on proper development of FAE and M cells, some interesting questions arise. One of them is; what is the impact of these regulatory function of $B$ cells under some autoimmune conditions dominated by humoral disturbances, such as systemic lupus erythematosus?

\section{Methods}

The authors examined knockout (KO) mice with targeted mutations that lack the following specific lymphocyte subsets: 1, the absence of B cells, due to $\mathrm{KO}$ of either the ? membrane segment (Igh-6) or JH segments of immunoglobulin genes (Ig)(JHD); 2, mice deficient in either a?T cells or d?T cells; and 3 , mice deficient in both a? and d?T cells. In addition, mice lacking both B and T cells as a result of the absence of RAG1 recombinase (RAG1 KO) were analyzed for the development of PPs by light and laser scanning microscopy and the numbers of $\mathrm{M}$ cells were also analyzed by scanning microscopy. Since substantial diminution of $\mathrm{M}$ cell numbers should lead to a strong functional impairment, mouse mammary tumor virus (MMTV), a classic retrovirus using M cells to enter GALT, was applied to analyze the involvement of $\mathrm{M}$ cells in retroviral transport from the intestinal lumen. To unmask the possible role of M cells in channeling MMTV through the intestinal wall, a bone marrow chimera approach was used (newborn Igh-6 or T cell receptor (TCR) KO mice as recipients of normal adult B6). 


\section{References}

1. Golovkina TV, Shlomchik M, Hannum L, Chervonsky A: Delineation of a further essential function of B cells: involvement in organogenesis. Science. 2000, 286: 1965-1968.

This PDF file was created after publication. 